\title{
Interférences
}

Ars scribendi

$10 \mid 2018$

Varia

\section{La narratio chez Cicéron doit-elle être brève pour persuader?}

\section{Marie Formarier}

\section{(2) OpenEdition}

Journals

Édition électronique

URL : http://journals.openedition.org/interferences/6007

DOI : 10.4000/interferences.6007

ISSN : $1777-5485$

Éditeur

HiSoMA - Histoire et sources des Mondes antiques

Référence électronique

Marie Formarier, "La narratio chez Cicéron doit-elle être brève pour persuader? », Interférences [En ligne], 10 | 2018, mis en ligne le 26 juillet 2018, consulté le 15 septembre 2020. URL : http:// journals.openedition.org/interferences/6007; DOI : https://doi.org/10.4000/interferences.6007

Ce document a été généré automatiquement le 15 septembre 2020

Tous droits réservés 


\title{
La narratio chez Cicéron doit-elle être brève pour persuader?
}

\author{
Marie Formarier
}

1 Pourquoi et comment les histoires parviennent-elles à nous persuader? La question passionnante de ce rapport entre la persuasion et la narration a été mise sur le devant de la scène notamment par le concept désormais galvaudé de «storytelling »; loin d'être une innovation contemporaine, ce procédé qui consiste à intégrer des récits dans le

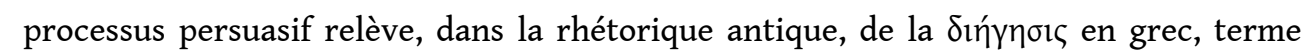
traduit en latin par «narratio ». Reprenant la rhétorique grecque dont il est l'héritier, Cicéron expose à plusieurs reprises, dans ses traités, une définition de narratio : il s'agit de «l'exposé de faits tels qu'ils se sont déroulés ou tels qu'ils ont pu se dérouler ${ }^{1}$ »; plus précisément, la narratio oratoire, employée dans la rhétorique délibérative et surtout judiciaire ${ }^{2}$, « contient l'exposé de la cause ${ }^{3}$ ». Elle permet à l'orateur d'élucider pour son auditoire les détails de l'affaire; elle intervient logiquement après l'exorde et avant la discussion à proprement parler ${ }^{4}$. En outre, « il convient qu'elle ait ces trois qualités : la brièveté, la clarté et la vraisemblance ${ }^{5}$ ». Derrière son apparente simplicité, cette définition de la narration oratoire, loin d'être aussi univoque que sa formulation laconique le laisse entendre, est en fait beaucoup plus complexe que ce que l'on pourrait croire à la première lecture. Elle recouvre en réalité des enjeux essentiels, tant esthétiques que pratiques.

2 En effet, comme le souligne à juste titre J. O'Bannion, la narratio suppose la maîtrise de procédés discursifs hétérogènes et complémentaires, relevant à la fois de la logique linéaire (respect de la chronologie des faits) et de la caractérisation éthique et pathétique : il s'agit d'élucider les faits, de replacer l'affaire dans son contexte, mais aussi de dresser le portrait des personnes concernées, de les faire parler grâce à des dialogues, de mettre sous les yeux du public les caractéristiques morales et émotionnelles qui ont pu les amener à mener telle ou telle action, etc. ${ }^{6}$. Cette richesse suppose, de la part de l'orateur, la maîtrise parfaite de son sujet et des divers procédés qui vont lui permettre d'atteindre son but: exposer la cause de façon brève, claire et vraisemblable, afin d'instruire et de persuader son auditoire. 
3 Se pose donc le problème du rapport que la narratio oratoire peut entretenir avec d'autres énoncés qui font appel aux mêmes procédés, comme le dialogue théâtral ou la description historique ; on est aussi en droit d'interroger, en conséquence, la finalité de la narratio: il ne s'agit pas seulement d'informer l'auditoire, mais d'amorcer, dès cet exposé des faits, la stratégie de persuasion ${ }^{7}$, qui repose tout à la fois sur la raison et les émotions. Par ailleurs, les trois vertus de la narratio déterminent des choix stylistiques qui amènent l'orateur à prendre parti, aux yeux de ses pairs, dans des discussions expertes qui peuvent sembler superficielles, mais qui, loin d'engager seulement des questions purement esthétiques, défendent aussi une vision et un usage de l'éloquence dans la sphère publique. À cela s'ajoutent le problème lié à l'évolution de la théorie cicéronienne, qui se détache de l'héritage isocratique pour mieux affirmer des convictions personnelles, fruit d'une réflexion menée sur le long terme et enrichie par l'expérience du terrain ${ }^{8}$, ainsi que la question corollaire: dans quelle mesure la pratique oratoire cicéronienne accompagne-t-elle, ou non, ces inflexions théoriques?

4 Le sujet est trop vaste pour pouvoir être traité ici de façon exhaustive ; j'attacherai donc mon attention plus précisément au concept de breuitas («brièveté »), l'une des trois vertus de la narratio oratoire. Les deux raisons qui m'amènent à ce choix sont simples : c'est sur ce point que Cicéron évolue le plus dans sa réflexion théorique, il suffit de comparer rapidement les différentes définitions de la narratio oratoire du De inuentione à l'Orator pour s'en rendre compte. D'autre part, la breuitas est au cœur d'une polémique assez vive dans laquelle Cicéron s'oppose à ses détracteurs quant à la définition de l'atticisme, et plus généralement du style oratoire. La breuitas fournit donc un bon angle d'approche pour examiner, dans un cadre qui reste circonscrit, les différents enjeux théoriques et pratiques de la narratio oratoire.

5 Pour ce faire, j'examinerai en premier lieu les définitions cicéroniennes et le commentaire qu'en fait Quintilien, instructif pour notre connaissance tant de la doctrine elle-même que du contexte esthétique dans lequel cette doctrine parvient, petit à petit, à se démarquer de la tradition isocratique et à affirmer son originalité. Je m'interrogerai plus précisément sur la place accordée par Cicéron à une citation de L'Andrienne de Térence : les différentes modalités de cette ressource littéraire dans les démonstrations successives illustrent de manière claire l'évolution de la doctrine cicéronienne concernant à la fois le statut et la finalité de la narratio oratoire. Enfin, je proposerai quelques relevés afin d'évaluer dans quelle mesure les critères quantitatifs qui définissent la breuitas, notamment le nombre de mots, sont appliqués dans différentes narrationes cicéroniennes. Une courte analyse comparative du Pro Caecina et du Pro Rabirio Postumo permettra de compléter ce premier bilan provisoire.

\section{Les définitions cicéroniennes de la narratio oratoire}

6 Le premier traité de rhétorique composé par Cicéron dans les années 84/83 offre une théorie fidèle aux sources grecques, en tout cas aux prédécesseurs d'Aristote, et très similaire à la Rhétorique à Hérennius". Sont distinguées trois catégories de narration, parmi lesquelles seule la première expose directement la cause elle-même (Cicéron, Inu., I, 27) :

Narratio est rerum gestarum aut ut gestarum expositio. Narrationum genera tria sunt: unum genus est, in quo ipsa causa et omnis ratio controuersiae continetur; alterum, in quo digressio aliqua extra causam aut criminationis aut similitudinis aut delectationis non 
alienae ab eo negotio, quo de agitur, aut amplificationis causa interponitur. Tertium genus est remotum a ciuilibus causis, quod delectationis causa non inutili cum exercitatione dicitur et scribitur.

«La narration est l'exposé des faits tels qu'ils se sont passés, ou tels qu'ils ont pu se passer. Il y a trois sortes de narration. La première embrasse la cause elle-même et l'ensemble du point de discussion. La seconde s'intercale comme une digression par rapport à la cause, et a pour objectif d'ajouter un moyen d'accusation, une analogie, un moment de détente (qui ne soit pas étranger à l'affaire dont il est question), une amplification. La troisième ne concerne pas les procès, il s'agit d'un agrément qui permet de s'exercer fort utilement, à l'oral comme à l'écrit ${ }^{10}$. »

7 Comme nous le verrons plus loin, le nom expositio ainsi que le verbe exponere reviendront dans d'autres passages où il sera question de la narration oratoire; ils définissent la première fonction de la narration, qui consiste à exposer les faits à la vue de tous. De plus, cette tripartition est opérée par Cicéron en vertu de l'utilité décroissante de ces narrations dans l'éloquence judiciaire. En effet, la première correspond précisément à l'exposé des faits, qui vise à instruire l'auditoire (docere). Il ne s'agit pas, pour l'orateur, d'être agréable, mais de délivrer une information nécessaire au bon déroulement du dispositif persuasif, et exhaustive, comme le suggère l'emploi de l'adjectif omnis. La deuxième catégorie de narration, en revanche, n'est pas nécessaire : à la périphérie de la cause (digressio aliqua extra causam), elle tisse toutefois un lien avec celle-ci, et permet, de façon contournée, de maintenir l'attention du public, en apportant des compléments d'information corrélatifs à la cause - une autre action de la personne concernée, d'autres actions semblables menées par d'autres personnes, l'histoire du lieu dans lequel l'affaire s'est déroulée, etc. Il s'agit en quelque sorte de faire comme si l'on parlait d'autre chose, alors même qu'on est toujours dans le sujet. On note que le divertissement est l'un des motifs légitimes qui peuvent amener l'orateur à se lancer dans une digressio narrative, même si la cause doit en circonscrire les contours (delectationis non alienae ab eo negotio quo de agitur) : la narratio permet non plus seulement d'instruire, mais aussi d'instaurer une connivence par le biais de l'agrément, du charme, de la séduction, voire de la plaisanterie (delectare). La troisième catégorie de narration, en revanche, est un pur produit littéraire, offrant un divertissement (delectationis causa), indépendamment de toute cause. Cette dernière narration se suffit à elle-même. Néanmoins, son statut d'exercice (exercitatio) suggère qu'elle joue le rôle d'une préparation en vue de la pratique des deux autres, en particulier dans la déclamation ${ }^{11}$.

8 La suite de la démonstration du De inuentione suit scrupuleusement le plan adopté par la Rhétorique à Hérennius ${ }^{12}$. Concernant le troisième genre de narration, qui ne touche pas l'éloquence judiciaire, Cicéron énumère la tripartition fabula / argumentum / historia, traduction latine du grec $\mu \tilde{v} \theta \circ \varsigma / \pi \lambda \alpha ́ \sigma \mu \alpha /$ i $\sigma \tau o p i ́ \alpha$. Cicéron précise ensuite les caractéristiques de la narration oratoire : elle occupe la deuxième partie du discours, venant après l'exorde, et doit comporter les trois qualités héritées de l'école d'Isocrate ${ }^{13}$ : la clarté, la vraisemblance et la brièveté (Cicéron, Inu., I, 28) :

Nunc de narratione ea, quae causae continet expositionem, dicendum uidetur. Oportet igitur eam tres habere res: ut breuis, ut aperta, ut probabilis sit.

«C'est maintenant le moment de parler de la narration qui expose la cause. Il faut qu'elle ait ces trois qualités : être brève, claire et vraisemblable ${ }^{14}$. "

Ces qualités sont présentées comme une norme à respecter (oportet), que le jeune Cicéron ne cherche pas à discuter, mais qu'il se contente d'exposer. 
9 En revanche, dans le De oratore rédigé trente ans plus tard, en 55, la forme du dialogue adoptée par Cicéron permet de débattre sur la pertinence des principes discutés ainsi que sur la légitimité de ceux qui les transmettent. Par conséquent, la définition de la narratio, si elle semble en tout point semblable à celle du De inuentione, ne répond pas du tout au même dispositif énonciatif ; Antoine, ici porte-parole de Cicéron, n'en assume aucunement l'auctorialité (Cicéron, de Orat., II, 80) :

Iubent enim [...] deinde rem narrare et ita, ut ueri similis narratio sit, ut aperta, ut breuis [...].

«Ils ordonnent [...] de raconter ensuite l'affaire de sorte que la narration soit vraisemblable, claire et brève ».

Si l'on replace cette définition dans le fil de la discussion qui anime Catullus et Antoine, on comprend que ceux qui ordonnent (iubent) de respecter ces trois principes issus de l'enseignement isocratique, ce sont les rhéteurs grecs. Or, ceux-ci sont l'objet d'une critique très sévère. Catullus rapporte ainsi l'histoire du sophiste Phormion qui aurait osé, devant le chef carthaginois Hannibal, tenir de longs discours sur l'art militaire, sans l'avoir lui-même pratiqué ; Catullus conclut que l'art de l'éloquence est encore souvent enseigné ainsi, par des gens qui ne le pratiquent pas ${ }^{15}$. Antoine surenchérit, en détaillant les préceptes transmis par ces rhéteurs grecs, qu'il méprise aussi pour leur méconnaissance $\mathrm{du}$ terrain: selon lui, les divisions qu'ils proposent sont superfétatoires, car évidentes ${ }^{16}$, ou bien abusives et erronées. C'est pour illustrer son propos critique qu'Antoine redonne la définition de la narratio (Cicéron, de Orat., II, 81 ; 83) :

Quae enim praecepta principiorum et narrationum esse uoluerunt, ea in totis orationibus sunt conseruanda. [...] Iam uero narrationem quod iubent ueri similem esse et apertam et breuem, recte nos admonent; quod haec narrationis magis putant esse propria quam totius orationis, ualde mihi uidentur errare [...].

«Les préceptes qu'ils ont énoncés pour l'exorde et la narration doivent être observés dans l'ensemble du discours. [...] Ils ordonnent que la narration soit vraisemblable, claire et brève, et ce conseil qu'ils nous donnent est juste. Mais quand ils considèrent que ces qualités sont plus propres à la narration qu'au reste du discours, ils se trompent complètement, je pense ».

Antoine exprime ici un jugement de valeur sur la norme imposée par les rhéteurs, qu'il remplace par de nouvelles règles dont il est le garant. L'objet de la critique est aisé à comprendre: les qualités de clarté, de vraisemblance et de brièveté sont certes adaptées à la narration, mais ne doivent en aucun cas être cantonnées à cette partie du discours. C'est à ce stade de la réflexion cicéronienne que la question de la breuitas devient primordiale, car elle cristallise à partir du De oratore cette défiance de plus en plus affirmée et assumée vis-à-vis des rhéteurs et de la tradition isocratique.

Dans les Partitiones oratoriae ${ }^{17}$, Cicéron va plus loin, puisqu'il déplace ce critère de breuitas à la périphérie de sa définition, se contentant de l'évoquer par la suite, en passant $^{18}$ (Cicéron, Part. 31-32) :

$F$ : Quid ? In narratione quae tandem obseruanda sunt?

P: Quoniam narratio est rerum explicatio et quaedam quasi sedes ac fundamentum constituendae fidei, ea sunt in ea seruanda maxime, quae etiam in relicuis fere dicendi partibus; quae partim sunt necessaria, partim adsumpta ad ornandum. Nam ut dilucide probabiliterque narremus, necessarium est; sed adsumimus etiam suauitatem. Ergo ad dilucide narrandum eadem illa superiora explanandi et illustrandi praecepta repetimus, in quibus sit breuitas ea quae saepissime in narratione laudatur [de qua supra dictum est].

«Bon et dans la narration, quelles sont les règles finalement à respecter?

- Puisque la narration est l'exposé des faits et que c'est sur elle, en quelque sorte, 
qu'on s'appuie pour instaurer la confiance, il faut surtout respecter les mêmes règles que pour les autres parties. Certaines sont nécessaires, d'autres relèvent de l'ornement. On fera donc un récit clair et vraisemblable, cela est nécessaire ; mais on y ajoutera aussi de la douceur. Pour faire une narration claire, je renvoie aux préceptes donnés plus haut sur la clarté et l'éclat du discours; c'est aussi à cet endroit qu'il est question de la brièveté, très souvent louée dans la narration ».

Cicéron père insiste avant tout sur la cohérence du discours : comme Antoine dans le De oratore, il considère que les qualités de clarté et de vraisemblance de la narratio, qui doivent être impérativement présentes dans cette partie du discours afin de conférer durablement à l'orateur un ethos crédible, sont en fait des éléments clefs pour l'ensemble du discours. Il ajoute à ces deux qualités l'agrément (suauitas), c'est-à-dire, pour reprendre les mots de L. Calboli-Montefusco, «le plaisir engendré chez les auditeurs, un plaisir qui capture leur âme et contribue à les persuader ${ }^{19}$ ».

La façon dont Cicéron introduit la qualité de brièveté retire à cette dernière l'importance qui lui était accordée jusqu'alors : placée hors de la définition en tant que telle et des préceptes nécessaires (quae partim sunt necessaria [...] dilucide probabiliterque narremus, necessarium est), elle apparaît comme un élément dispensable. La tournure passive (quae saepissime in narratione laudatur) suggère que Cicéron père fait simplement le constat que cette qualité est louée, sans préciser si c'est à tort ou à raison : cette assertion n'implique aucun jugement personnel. En somme, outre l'accent mis sur la clarté et la vraisemblance, la narratio ne se distingue pas du reste du discours; ses caractéristiques sont conformes aux qualités du style (elocutio) : la clarté, la brièveté, la vraisemblance, l'évidence et l'agrément ${ }^{20}$. Cette présence de l'évidence, comprise au

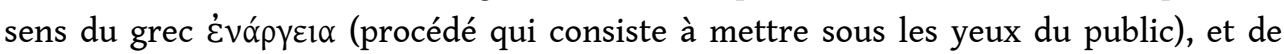
l'agrément ${ }^{21}$ dans la définition de la narratio suggère que Cicéron élargit la perspective, en incorporant d'autres préceptes dans la définition traditionnelle de la narratio, mais aussi en insistant sur le fait qu'ils sont présents dans l'ensemble du discours.

Dans l'Orator, Cicéron poursuit cette logique en laissant de côté ce plan scolaire qui suit l'ordre des parties du discours. Comme le souligne C. Guérin, dans ce traité qui suit la querelle atticiste, "Cicéron élabore une norme nouvelle permettant non plus d'analyser ces différents modes d'expression, mais bien de les hiérarchiser : à une excellence conçue de façon monolithique, s'oppose l'infinie variation des styles dégradés ${ }^{22} »$. L'orateur idéal est celui qui maîtrise les trois styles, qui sait les mêler, et surtout, qui parvient à captiver son auditoire. Si la définition de la narratio oratoire suit la tripartition traditionnelle ${ }^{23}$, l'accent est ainsi mis principalement sur la relation qui s'établit entre l'orateur et son public. La brièveté n'est qu'une qualité parmi d'autres, à n'employer que lorsque la situation l'exige ${ }^{24}$. Pour reprendre les mots d'A. Michel, « la breuitas est souvent utile. L'on doit en user avec à-propos. Mais il serait absurde d'en user toujours ${ }^{25} \gg$. À la lecture du portrait de l'orateur idéal ${ }^{26}$, plein de fougue, capable de feinter, d'imiter les autres, de prendre à partie les juges ou l'auditoire, libre de répéter, d'hésiter, d'inventer des dialogues, des remontrances ou des supplications, on mesure le chemin parcouru en trente ans. Cicéron assume désormais sa prise de position quant à la place limitée de la breuitas dans la narratio, tout en continuant d'argumenter dans les nombreux passages où il s'en prend de manière virulente aux néo-atticistes. 


\section{La breuitas en question} de rendre une narratio brève : choisir judicieusement les premiers et les derniers faits exposés $^{27}$, et les synthétiser ${ }^{28}$; ne faire aucune transition ${ }^{29}$, aucune digression ${ }^{30}$, aucune répétition ${ }^{31}$; jouer sur l'esprit de déduction ${ }^{32}$; s'en tenir à ce qui est favorable, en taisant ce qui est nuisible ou même neutre pour l'affaire ${ }^{33}$. Cette liste permet de comprendre ce que Cicéron entend par breuitas dans ce premier traité : le fait de limiter tout d'abord les informations, et ensuite l'étendue du propos, notamment le nombre de mots. Les deux paramètres sont essentiels : Cicéron raille ainsi les orateurs qui pensent être brefs parce qu'ils limitent la longueur de leur narration, alors même qu'ils auraient dû commencer par trier les informations, et ne retenir que celles qui sont nécessaires à la bonne intelligence de la cause ${ }^{34}$. éléments : la nécessité de limiter le nombre de mots et la sélection des composantes de la narration en fonction seulement de leur pertinence informative. Dans cette démonstration et les conséquences qu'il en tire, il propose, comme nous allons le voir, une vision originale de la narration.

Dans le De inuentione comme dans le De oratore, Cicéron cite L'Andrienne de Térence pour illustrer son propos. Or, l'usage de cette référence littéraire diffère en tous points dans les deux passages. En effet, dans le De inuentione, Cicéron l'emploie comme un exemple d'argumentum, c'est-à-dire une narration qui n'a aucun rapport avec la rhétorique, et qui rapporte des faits fictifs mais vraisemblables ${ }^{35}$. Dans le De oratore, Cicéron déplace la citation dans sa définition de la narratio oratoire, non pour illustrer, comme on pourrait s'y attendre, le précepte de vraisemblance, dénominateur commun de la comédie et de la narratio oratoire ${ }^{36}$, mais pour discuter du sens qu'il faut donner à la notion de breuitas.

Cicéron, Inu., I, 27 :

Argumentum est ficta res, quae tamen fieri potuit. Huiusmodi apud Terentium : «Nam is postquam excessit ex ephebis, [Sosia...]».

«La fiction est une histoire inventée qui aurait cependant pu se passer. Par exemple chez Térence : "Depuis qu'il est sorti de l'éphébie, Sosie..." "

Cicéron, de Orat., II, 326-328 :

Narrare uero rem quod breuiter iubent, si breuitas appellanda est, quom uerbum nullum redundat, breuis est L. Crassi oratio; sin tum est breuitas, quom tantum uerborum est quantum necesse est, aliquando id opus est; sed saepe obest uel maxime in narrando, non solum quod obscuritatem adfert, sed etiam quod eam uirtutem, quae narrationis est maxima, ut iucunda et ad persuadendum accommodata sit, tollit. Videant illa: "nam is postquam excessit ex ephebis...", quam longa est narratio! Mores adulescentis ipsius et seruilis percontatio, mors Chrysidis, uoltus et forma et lamentatio sororis, reliqua peruarie iucundeque narrantur. Quod si hanc breuitatem quaesisset : " effertur, imus, ad sepulcrum venimus, in ignem imposita est » decem versiculis totum conficere potuisset; quamquam hoc ipsum " effertur, imus", concisum est ita, ut non breuitati seruitum sit, sed magis uenustati. Quod si nihil fuisset, nisi "in ignem imposita est ", tamen res tota cognosci facile potuisset. Sed et festiuitatem habet narratio distincta personis et interpuncta sermonibus, et est et probabilius, quod gestum esse dicas, quom quem ad modum actum sit exponas, et multo apertius ad intellegendum [est], si constituitur aliquando ac non ista breuitate percurritur. "Quand ils ordonnent de raconter l'affaire de façon brève, si l'on considère que la brièveté doit être définie comme le fait qu'il n'y ait aucun mot de trop, alors le style de L. Crassus est bref. Mais si la brièveté est le fait de n'employer que le nombre de 
mot strictement nécessaire, elle peut certes s'avérer utile, mais souvent, elle est nuisible, surtout quand il s'agit de la narration, car elle y apporte de l'obscurité et en retire la plus grande qualité : l'agrément et la force persuasive. Il n'y a qu'à voir ces vers : "dès qu'il fut sorti de l'éphébie..." : comme cette narration est longue ! On y fait le récit varié et charmant du caractère du jeune homme lui-même, des questions posées aux esclaves, de la mort de Chrysis, du visage, de la beauté et des larmes de la sœur, et de toute la suite. Si l'auteur avait partout recherché la brièveté de ces vers : "On la soulève, nous marchons, nous arrivons, on la dépose sur le bûcher", il aurait pu tout faire tenir en dix petits vers; et pourtant, la concision de ce "on la soulève, nous marchons" tient moins de la brièveté que de la grâce. Et même, s'il n'y avait eu que "on la dépose sur le bûcher", cela aurait suffi pour connaître toute l'histoire. Mais c'est bien de l'agrément que contient une narration animée de personnages et scandée par des dialogues; de plus, les faits sont plus vraisemblables quand on dit comment cela s'est passé, et plus aisés à comprendre si on fait des pauses, au lieu de courir tout le temps au nom de cette fichue brièveté ».

18 Ce sont les deux extraits essentiels pour comprendre l'évolution de la réflexion cicéronienne au sujet de la breuitas, et plus largement sur le statut et la finalité de la narratio oratoire, qui déterminent les choix stylistiques à opérer. Alors que, dans le $D e$ inuentione, Cicéron se contente de citer le vers qui amorce la narratio de Simon dans L'Andrienne (An., I, 1, 51) comme un simple exemple d'argumentum, il livre dans le De oratore un véritable commentaire littéraire, dont l'objectif est de liquider définitivement le problème de cette "mauvaise» breuitas. Cette narratio dans L'Andrienne est, de fait, remarquable; le récit, mené par Simon et scandé par les questions de l'affranchi Sosie, occupe toute la première scène de la comédie. L'habileté de Térence tient au fait que cet échange badin entre Simon et Sosie permet de donner toutes les informations nécessaires aux spectateurs pour prendre connaissance de l'argument de la pièce : le portrait moral du jeune Pamphile, la mort de la courtisane Chrysis, la découverte par Simon, à l'occasion des obsèques, de la liaison de Pamphile et de Glycère, sœur présumée de la défunte, la remise en cause du mariage de Pamphile avec la fille de Chrémès, la stratégie à adopter pour rétablir la situation, et les rôles qui devront être tenus par Simon et Sosie.

19 Le raisonnement mené par Cicéron dans ce passage du De oratore est très dense. L'Arpinate commence par énoncer deux définitions de la breuitas. La première consiste à peser ses mots et à canaliser le flux du discours (uerbum nullum redundat). Cicéron ne donne pas explicitement son assentiment, il évoque seulement la figure exemplaire de l'orateur L. Crassus, sur laquelle je vais revenir. En revanche, il critique ouvertement la seconde définition, qui caractérise la breuitas en vertu d'un critère purement quantitatif : le nombre de mots (tantum uerborum est quantum necesse est). Or, limiter le nombre de mots rend le discours obscur et excessivement sec, au point de lui retirer tout charme et toute force persuasive (eam uirtutem, quae narrationis est maxima, ut iucunda et ad persuadendum accommodata sit ${ }^{37}$. Cette éloquence qui court, sans s'accorder aucune pause (ista breuitate percurritur), est celle des orateurs qui se disent attiques, mais qui, selon Cicéron, ne font qu'assécher l'éloquence au point de la rendre à la fois inélégante et inefficace ${ }^{38}$. Or, comme la narratio oratoire n'a pas pour seul objectif d'informer, mais constitue également le premier rouage du dispositif persuasif, en charmant le public (delectare), ce genre de brièveté, qui consiste à limiter le nombre de mots, n'est pas à utiliser systématiquement. au sujet de la narratio de L'Andrienne mais aussi l'exemple de L. Crassus permettent de 
mieux en comprendre les caractéristiques. Tout d'abord, le procédé qui consiste à dire beaucoup en peu de mots vise davantage à frapper l'esprit du public qu'à observer un souci d'économie. En atteste l'exemple du «on la soulève, nous marchons " (effertur, imus) : la concision de la formule en fait toute la grâce (concisum est ita, ut non breuitati seruitum sit, sed magis uenustati ${ }^{39}$ ). La rapidité avec laquelle les deux images se succèdent (la levée du corps, le cortège), soutenue par la parataxe et le changement énonciatif brutal, permet à Térence d'informer le spectateur sans l'ennuyer : en peu de mots, tout est dit. Mais ce genre de procédé, qui répond finalement à la définition la plus courante de la breuitas, n'est pas systématique, et ne constitue pas l'objectif principal de la démarche stylistique. Sinon, Térence "aurait pu tout faire tenir en dix petits vers", voire en une seule formule. En revanche, l'agrément (festiuitas), reconnu dans le De inuentione comme un caractère de l'argumentum, devient ici la clef de voûte de la narratio oratoire. Il repose sur les mêmes éléments dans les deux cas de figure: la variété des personnages et la présence du dialogue (festiuitatem habet narratio distincta personi et interpuncta sermonibus $)^{40}$. Le plaisir des auditeurs est ainsi suscité à la fois par la maîtrise des divers procédés stylistiques de l'évidence - caractérisation des personnages et dialogues - et par la variété, antidote contre l'écœurement et l'ennui ${ }^{41}$. Le charme procuré par cette mise en scène facilite la vraisemblance, parce que l'auditeur comprend exactement comment les choses se sont passées (probabilius...), et la clarté (apertius...), du fait que l'orateur ne se sent pas pressé par le temps ${ }^{42}$.

La narratio mise en scène dans la comédie et la narratio oratoire ont donc en commun un objectif : rendre intelligibles et intéressants, par le récit, une situation et des faits. Les procédés pour atteindre cet objectif relèvent de la technique narrative et de la stylistique, et ont pour point commun de produire de la variété et de l'agrément : en font partie le discours rapporté et les descriptions physiques, morales et émotionnelles des personnes concernées. L'exemple de L. Crassus permet de mieux comprendre comment une narratio oratoire peut fonctionner de la sorte. Dans le Brutus, composé une petite dizaine d'années après le De oratore, Cicéron rapporte en détails une affaire de testament qui opposait Manius Curius et Scaevola ${ }^{43}$. Scaevola défend son point de vue dans un style efficace et concis (Cicéron, Brut. 197):

Quae quidem omnia cum perite et scienter sumpta breuiter et presse et satis ornnate et pereleganter diceret, quis esset in populo, qui aut exspectaret aut fieri posse quicquam melius putaret ${ }^{44}$ ?

« comme tout son discours respirait l'expertise et la science, l'esprit de synthèse, avec ses formules brèves et denses, bien ornées avec soin! Qui, dans la foule, aurait pu attendre ou même imaginer mieux?»

C'était sans compter L. Crassus, l'avocat de la partie adverse (Cicéron, Brut. 197-198) :

At uero, ut contra Crassus ab adulescente delicato, qui in littore ambulans scalmum repperisset ob eamque rem aedificare nauem concupiuisset, exorsus est, similiter Scaeuolam ex uno scalmo captionis centumuirale iudicium hereditatis effecisse, hoc in illo initio consecutus, multis eiusdem generis sententiis delectauit animosque omnium qui aderant in hilaritatem a seueritate traduxit ; quod est unum ex tribus dixi ab oratore effici debere. [...] Haec cum grauiter tum ab exemplis copiose, tum uarie, tum etiam ridicule et facete explicans, eam admirationem assensionemque commouit, dixisse ut contra nemo uideretur ${ }^{45}$. «Mais ce fut au tour de la partie adverse : Crassus commença par le récit d'un jeune homme délicat, qui avait trouvé, lors d'une promenade, une cheville d'aviron sur la plage et qui avait eu ainsi l'idée de fabriquer un bateau; il fit la comparaison avec Scaevola, qui, à partir de l'unique cheville du "piège", avait réclamé le jugement des Centumvirs sur tout un héritage. Il poursuivit ainsi le début de son discours; grâce à de nombreuses formules du même genre, il charma son public et amena tous les cœurs de la sévérité à la joie. Cela correspond à l'une des trois tâches de 
l'orateur [...]. Il donnait ses explications avec sérieux, en multipliant les exemples, variant les procédés, en faisant même parfois des bons mots et des plaisanteries. Il provoqua une telle admiration et un tel assentiment qu'il semblait qu'aucun contradicteur n'avait pris la parole ». pittoresque, le cadre est posé (in littore...), l'adjectif delicatus suggère également que l'orateur a eu le souci de caractériser le personnage principal ; tout le début du discours est ainsi construit sur une comparaison (similiter...). Crassus prend visiblement son temps, et pourtant, Cicéron qualifie son éloquence de brève (breuis est L. Crassi oratio) : c'est que chaque mot a son utilité, et surtout, que le public ne voit pas le temps passer. L'atmosphère s'est détendue (in hilaritatem a seueritate...). Le charme opère (delectauit), la persuasion est en marche : la variété du style permet à Crassus de confirmer sa victoire, le public est conquis. l'orateur parvient à diriger les cœurs et les esprits à son gré est tout à fait emblématique de la perspective adoptée par Cicéron depuis le De oratore, notamment dans sa perception de la narratio oratoire. Tout d'abord, cette interaction est une composante essentielle dans le processus de persuasion; comme le souligne J. M. May, "persuasion is generally achieved only when an orator can relate closely to the customs, tastes, fears, and desires of his audience ${ }^{46} »$. En outre, l'argument selon lequel les réactions du public priment sur les avis experts émane d'une stratégie habile menée par Cicéron dans la querelle qui l'oppose au néo-atticistes : selon les mots de C. Guérin, « l'argument cicéronien, directement opposé à la posture atticiste qui critique le style ample au nom du goût - selon une analyse évidemment élitaire et esthétisante -, fait du public, et donc de l'efficacité, la pierre de touche ultime de la qualité oratoire ${ }^{47} »$. Dans cette perspective, Cicéron va même jusqu'à prôner des modifications profondes dans la démarche d'expertise: cette dernière doit être inaugurée par l'appréciation de la prestation, notamment de la qualité de l'interaction entre l'orateur et le jury, indépendamment du contenu discursif (Cicéron, Brut. 200) :

Videt oscitantem iudicem, loquentem cum altero, nonnumquam etiam circulantem, mittentem ad horas, quaesitorem ut dimittat rogantem; intellegit oratorem in ea causa non adesse, qui possit animis iudicum admouere orationem tamquam fidibus manum. Idem si praeteriens aspexerit erectos intuentes iudices, ut aut doceri de re idque etiam uultu probare uideantur, aut ut auem cantu aliquo sic illos uiderit oratione quasi suspenso teneri, aut, id quod maxime opus est, misericordia, odio, motu animi aliquo perturbatos esse uehementius, ea si praeteriens, ut dixi, aspexerit, si nihil audiuerit, tamen oratorem uersari in illo iudicio et opus oratorium fieri aut perfectum iam esse profecto intelleget ${ }^{48}$.

« Il voit que les juges bâillent, discutent entre eux, se lèvent même parfois pour se dégourdir les jambes, demandent l'heure, réclament au président de lever l'audience : il comprend que l'orateur dans cette cause n'est pas capable de faire jouer les mots sur le cœur des juges comme la main sur une lyre. S'il passe son chemin et aperçoit des juges debout, leur regard attentif réclamant les informations sur l'affaire et l'expression approbatrice de leur visage, ou bien des juges suspendus aux lèvres de l'orateur, comme un oiseau captivé par un chant, ou bien même, ce qui est le plus essentiel, des juges violemment agités par la compassion, la haine ou quelque autre émotion, eh bien, s'il aperçoit cela, comme je l'ai dit, sans avoir rien entendu, il comprendra que c'est bien un "orateur" à qui l'on a affaire dans ce procès et une "œuvre oratoire" qui va s'accomplir ou qui s'est même déjà réalisée ". 
discours est donc mesuré à sa capacité d'agir sur le public: un récit mené avec brio, comme celui de Térence dans L'Andrienne ou celui de Crassus dans l'histoire d'héritage de Scaevola, est bien plus efficace qu'un exposé précis, bref, mais ennuyeux: les personnages, les actions, les dialogues permettent de charmer les juges, mais aussi de faire comprendre plus nettement l'affaire, de susciter de l'intérêt et de la curiosité, et, mieux encore, d'émouvoir, par le biais d'un procédé mimétique qui relève de l'euidentia.

Comme le souligne A. Michel, "l'orateur ne se borne pas à être intelligible, il rend évident tout ce qu'il dit ${ }^{50} »$. Il s'agit de mettre sous les yeux du public ${ }^{51}$ l'affaire dont il est question, en suscitant une image mentale. Ainsi, pour Quintilien (Inst., IV, 2, 64) :

euidentia in narratione, quantum ego intellego, est quidem magna uirtus, cum quid ueri non dicendum, sed quodammodo etiam ostendendum est

« l'évidence dans la narration, au sens où je l'entends [c'est-à-dire l'équivalent de l' enargeia grecque], est une grande qualité lorsqu'il s'agit non pas seulement de dire la vérité, mais aussi, d'une certaine façon, de la montrer ${ }^{52}$ ».

La vérité elle-même concerne autant les faits exposés que les émotions représentées dans les portraits et les dialogues, puis incarnées par l'orateur lui-même et suscitées, enfin, chez le public. On retrouve là le processus de mimesis tel qu'il est défini depuis Aristote $^{53}$. Or, si la narratio oratoire a pour sujet des faits réels, et non imaginaires comme la narratio comique ${ }^{54}$, il n'en reste pas moins que la réussite de cette mimesis est primordiale, car elle permet au public de s'approprier les faits, moins par la raison que par les émotions ${ }^{55}$, et à l'orateur «de devenir intime avec son public ${ }^{56}$ ». L'usage d'un exemple comique dans le De oratore, au même titre que ces comparaisons employées dans cet extrait du Brutus, évoquant la lyre du musicien (tamquam fidibus manum) ou bien l'oiseau captivé par un chant (auem cantu aliquo...), souligne l'analogie des procédés qui guident la narratio en rhétorique et au théâtre. Lorsque le public est conquis, « on comprend alors que c'est un Roscius qui est sur scène $\mathrm{e}^{57} »$.

26 À partir du De oratore, Cicéron définit donc le statut et la finalité de la narratio oratoire ainsi : il s'agit d'un récit visant à susciter et maintenir l'intérêt du public pour l'affaire dont il est question, au moyen de procédés mimétiques issus du théâtre (représentation morale et émotionnelle). L'agrément devient par conséquent la vertu principale de cette partie du discours. La clarté et la vraisemblance en découlent logiquement, comme dans la narratio comique de L'Andrienne. La breuitas, comprise comme un procédé technique de composition qui vise à l'économie de mots, devient une caractéristique accessoire, et non systématique, de la narratio oratoire. En revanche, elle reste une nécessité légitime si elle est associée à l'agrément et si on la comprend plutôt au sens de «brièveté ressentie ».

27 Par conséquent, en vertu d'une inflexion générale de la doctrine cicéronienne de plus en plus attentive à l'interaction entre l'orateur et son public, la brièveté de la narration oratoire devient une qualité de la réception du discours par le public. Quintilien reprend cette idée et l'explicite ainsi (Quintilien, Inst., IV, 2, 46) :

Nam et fallit uoluptas, et minus longa quae delectant uidentur, ut amoenum ac molle iter,

etiamsi est spatii amplioris, minus fatigat quam durum aridumque compendium.

«Le plaisir fait illusion, et un discours qui charme semble moins long, de même qu'un itinéraire plaisant et facile, même s'il est plus long, fatigue moins qu'un raccourci difficile et aride. "

L'évolution de cette définition de la breuitas, qui s'inscrit dans un changement de perspective plus global sur la vision et l'usage de l'éloquence dans la sphère publique, s'accompagne-t-elle d'un changement de pratique chez Cicéron? 


\section{La breuitas dans les plaidoyers de défense}

Analyser la pratique de la breuitas dans les discours de Cicéron est un projet d'envergure, qui ne peut être mené ici dans son intégralité. Afin de lancer quelques pistes de réflexion, je propose de m'en tenir à des relevés quantitatifs simples, qui permettent de donner un premier aperçu, ainsi qu'à une courte étude comparative de deux narrationes qui présentent le même profil statistique, mais qui appartiennent à deux périodes différentes dans la carrière de Cicéron : le Pro Caecina (env. 69/67) et le Pro Rabirio Postumo (54).

Le choix du corpus a été mené de la façon suivante : afin de conserver une certaine cohérence, je n'ai pris en considération que les plaidoyers de défense dans lesquels la narratio, comprise comme une partie distincte du discours, est placée entre l'exorde et la discussion. Je laisse donc de côté les discours de défense dans lesquels la narratio ainsi définie n'intervient pas, en particulier lorsque Cicéron se charge seulement de la dernière partie du plaidoyer, et les discours d'attaque, ainsi que les discours d'apparat prononcés dans la dernière période en faveur de César. Ce choix peut être sujet à discussion; Cicéron lui-même remarque cependant que les procédés divergent selon que la narration privilégie la dignité ou la véhémence ${ }^{58}$. Enfin, je considère ici que l'écart entre discours prononcé et discours publié ${ }^{59}$ constitue certes un obstacle, mais d'une ampleur limitée. En effet, même si les narrationes ont été retravaillées, elles correspondent à des choix esthétiques et stylistiques susceptibles d'illustrer l'évolution doctrinale concernant la breuitas.

Comme je l'ai montré, la breuitas définie comme la restriction du nombre de mots et d'informations est de moins en moins prépondérante dans la définition de la narratio. La première question qui se pose concerne donc cette évolution doctrinale: se manifeste-t-elle sur le plan quantitatif dans les discours? Des analyses stylistiques de discours cicéroniens ont déjà été menées précédemment ${ }^{60}$, en particulier par L. Laurand (1965), W. R. Johnson (1971), G. Achard (1981), J. Aumont (1996) ou encore M. voN ALBRECHT (2003). Les méthodes quantitatives adoptées notamment par W. R. Johnson et J. Aumont, bien plus complexes que celle que j'ai employée ici, ont permis de montrer les avantages mais aussi les limites des relevés statistiques ${ }^{61}$. Ces derniers fournissent en effet un matériau indispensable, qui demande cependant à être complété par une analyse plus fine, à l'échelle de la phrase.

Le premier relevé permet de visualiser les profils statistiques des différentes narrationes, définis selon le pourcentage des divers types d'énoncés: très brefs (1-5 mots), brefs (6-10 mots), moyens (11-20 mots), longs (21-30 mots) et très longs (plus de 30 mots). 


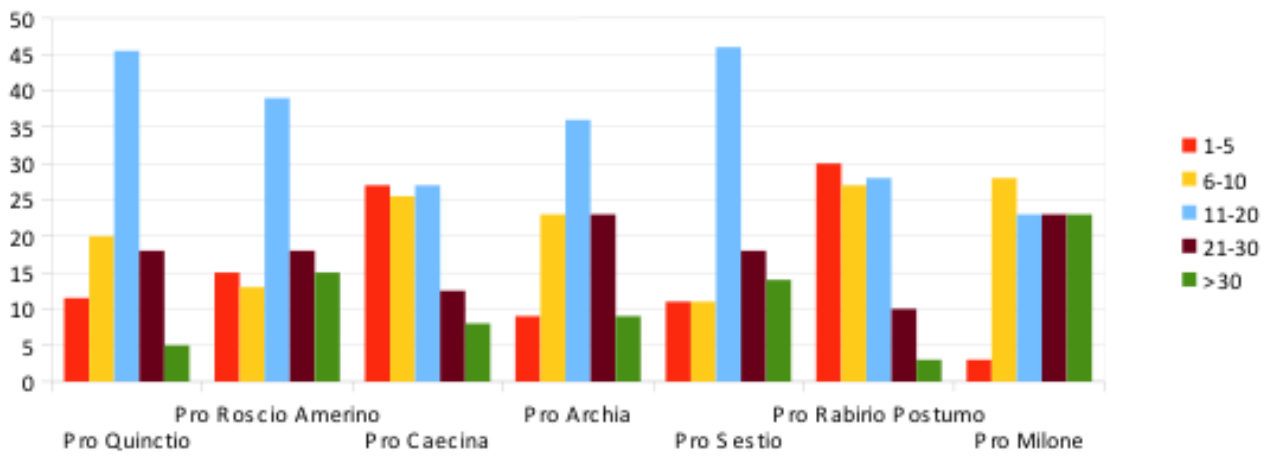
discours, allant de $3 \%$ dans le Pro Milone à $30 \%$ dans le Pro Rabirio Postumo, pourtant de la même période. Il en va de même pour les énoncés très longs (plus de 30 mots). La seule donnée invariable, si l'on excepte le Pro Milone, est la prédominance des énoncés moyens (11-20 mots). Le profil statistique des différents discours nous inviterait cependant à regrouper les discours sans tenir compte de la diachronie : le Pro Quinctio $(11,5 \%-20 \%-45,5 \%-18 \%-5 \%)$ et le Pro Archia $(9 \%-23 \%-36 \%-23 \%-9 \%)$; le Pro Roscio Amerino (15\% - $13 \%-39 \%-18 \%$ - $15 \%$ )et le Pro Sestio $(11 \%-11 \%-46 \%$ $18 \%-14 \%)$; le Pro Caecina ( $27 \%-25,5 \%-27 \%-12,5 \%-8 \%$ ) et le Pro Rabirio Postumo $(30 \%-27 \%-28 \%-10 \%-5 \%)$. Le Pro Milone (3\%- $28 \%-23 \%-23 \%-23 \%$ ) se distingue de tous les autres. Si l'on considère que les discours de défense mettent en œuvre une «éloquence fonctionnelle [...] étroitement liée aux conditions politiques [qui] dépend d'abord de la situation sociale de l'orateur ${ }^{62}$ ", cette première observation appellerait une recherche supplémentaire sur la parenté, ou non, des dispositifs persuasifs dans chaque binôme. Néanmoins, aussi séduisante soit-elle, cette hypothèse doit être appréhendée avec beaucoup de précaution. En effet, le second relevé, qui permet de comparer le nombre moyen de mots par énoncé dans la narratio et dans l' exordium, ne coïncide pas avec ces profils statistiques. 
Diagramme 2. Nombre moyen de mots par énoncé dans l'exordium (d'après les tableaux de JOHNSON 1971, p. 67) et dans la narratio.

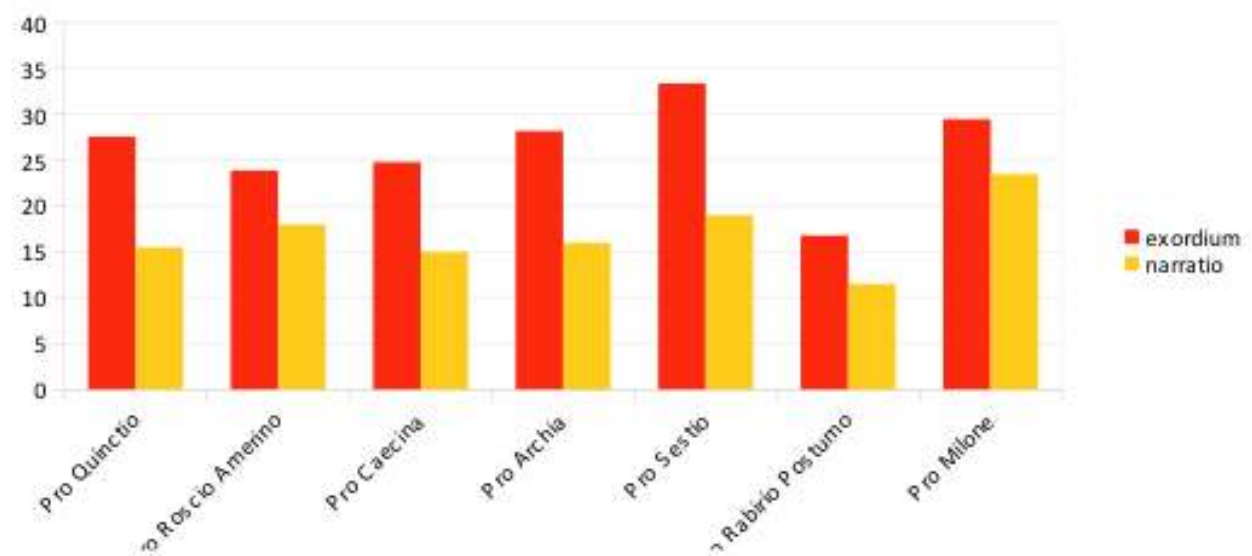

Ici encore, aucune tendance diachronique ne peut être dégagée, si ce n'est que le nombre moyen de mots par énoncé est systématiquement plus faible dans la narratio que dans l'exordium. La seule conclusion que l'on puisse tirer de ces résultats est donc que Cicéron prend garde à écourter les énoncés dans la narratio, conformément au principe de breuitas. Les trois discours dans lesquels l'écart est le plus faible entre l' exordium et la narratio sont le Pro Roscio Amerino (6 mots), le Pro Rabirio Postumo (5 mots) et le Pro Milone (6 mots). Ici encore, une comparaison du dispositif persuasif et des procédés stylistiques pourrait apporter un complément intéressant aux statistiques.

5 Deux constats peuvent être tirés de ces relevés finalement assez décevants. Tout d'abord, s'il en fallait une preuve, ils illustrent le fait que l'excellence du style ne peut, en aucun cas, se résumer à l'application stricte de préceptes, mais qu'elle relève, au contraire, de la capacité de l'orateur à s'adapter. Cela est d'autant plus vrai dans l'éloquence judiciaire : «ce lien entre style et fonction a une conséquence capitale sur la doctrine stylistique, dans la mesure où elle transforme le style, qui était la marque d'une individualité, en une capacité6 ${ }^{3} »$. Du point de vue épistémologique, cette malléabilité stylistique, que semble manifester la variabilité des statistiques, nous invite à beaucoup de prudence dans nos analyses. Comme le souligne C. P. Craig, «the key to discussion of style as a means of persuasion is exactly the interrelation of stylistic phenomena with a unique persuasive context. As a result, any synthesis runs an immediate risk of seeming reductive and dubious ${ }^{64} \%$.

Ces précautions étant prises, je propose néanmoins de mener une comparaison stylistique entre deux discours dont le profil statistique est proche. Le premier discours est le Pro Caecina, plaidé avant 67 ; il s'agit d'une affaire complexe de droit civil, plus précisément d'héritage, qui oppose Cécina, le client de Cicéron, à Ébutius. S. Usher souligne le soin apporté par Cicéron dans la narratio de ce discours : « a clear narrative, including the essential details (10-23), is very necessary in an inheritance case. In addition to the facts, this narrative contains a dialogue ${ }^{65} »$. Le second discours est le Pro Rabirio Postumo, plaidé en 54 dans le cadre de l'affaire Gabinius. Ce dernier a apporté, malgré l'interdiction du Sénat, une aide armée et financière à Ptolémée XIII. Il est condamné à son retour à Rome. Incapable de s'acquitter de ses dettes envers l'État, il est exilé. Rabirius, ancien intendant du roi d'Égypte, et en vertu de la lex Julia de repetundis, est assigné en paiement de cette somme que Gabinius n'avait pas été capable 
de rendre. Réticent, Cicéron s'engage à le défendre sur l'insistance de Pompée. On le voit, alors même que le profil statistique de ces deux discours est analogue, leur fonction, déterminée par des circonstances distinctes, est très différente : le premier, plaidé en début de carrière, défend une cause privée et un client que l'avocat connaît personnellement et apprécie; le second concerne des enjeux politiques, auxquels Cicéron se mêle sans enthousiasme.

Dans ces deux narrationes, la brièveté semble avoir deux fonctions. En effet, elle permet tout d'abord de rapporter de façon synthétique des événements passés, antérieurs à l'affaire, mais aussi les actions qui font l'objet du jugement. En outre, elle constitue une arme efficace dans la caractérisation éthique de l'adversaire et dans l'expression de l'indignation.

La breuitas permet donc à Cicéron d'évoquer rapidement les événements passés. Dans le Pro Caecina notamment, c'est ainsi que Cicéron rapporte l'histoire familiale de Cécina, en particulier celle de sa femme défunte, Césennia.

Cicéron, Caec. 12 :

Sed hunc fructum mature [fōrtūnā ăděmit]. // 6 [spondée + péon $1^{\text {er }]}$

Nam breui tempore M. Fulcinius adu[lēscēns mōrtŭŭs est];// 8 [spondée + péon $1^{\mathrm{er}}$ ]

heredem P. Cae[sēnnīūm fēcit] ; // 4 [crétique + spondée] uxori grande [pōndŭs ārgēnti] / matrique partem maiorem bono[rūm lēgāuit]. // 9 [crétique + spondée] + [dispondée]

Itaque in partem mulie[rēs uŏcātāe sunt]. // 6 [crétique + spondée]

«Mais la fortune lui retira bientôt ce fruit. De fait, peu de temps après, le jeune M. Fulcinius mourut. Son héritier était P. Césennius. Il léguait à son épouse une grosse quantité d'argent et à sa mère une part plus importante de ses biens. C'est ainsi que les deux femmes furent appelées pour la succession. »

Cicéron, Caec. 17 :

Quasi id aliter fie[rī ŏpōrtŭĕrit]. // 5 [trochée + péon $1^{\mathrm{er}}$ ]

Cum omnia ita facta essent, / quem ad modum nos defendimus, /

Caesennia fundum posse[dīt lŏcāuītque] ; // [crétique + spondée]

neque ita multo post A. Cae[cīnāe nūpsit]. // 7 [dispondée]

$V t$ in pauca conferam,/ testamento fac [tō mŭlīèr mŏrĭtur].// 8 [dactyle + péon $1^{\mathrm{er}}$ ]

«Comme si la situation avait pu être différente! Tandis que tout se déroulait ainsi que nous venons de le défendre, Césennia prit possession du domaine et s'y installa. Peu de temps après, il épousa A. Cécina. Et en un mot, son épouse meurt après avoir fait le testament. »

Le style, malgré la brièveté des énoncés, reste fluide grâce à l'emploi de chevilles (coordination ou subordination). L'usage du péon $1^{\mathrm{er}}$ dans les clausules ajoute, par la présence des trois brèves successives, une certaine légèreté rythmique, propre à renforcer l'impression de brièveté. La mort de Césennia, mise en avant par l'incise (ut in pauca conferam) et l'irruption du présent de l'indicatif (moritur), marque un tournant dans la narratio, car c'est à partir de cet événement que s'enclenche la stratégie d'Ébutius, qui va s'efforcer d'accaparer les terres censées revenir à Cécina. Dans le Pro Rabirio Postumo, de même, Cicéron rappelle les services rendus par son client à Ptolémée avant l'affaire, en 59 :

Cicéron, Rab. Post. 4 :

Cui egenti et rogandi hic infelix pe[cūnīām crēdǐdit]. // 8 [dicrétique]

Nec tum primum ; // 3

nam regnanti crediderat absens ; // 4

nec temere se [crēděrě pŭtābat] // 5 
«Comme Ptolémée était dans le besoin et qu'il le sollicitait, notre client, dans son malheur, lui prêta de l'argent. Et ce n'était pas la première fois. En son absence, il lui avait fait crédit lorsqu'il était sur le trône. Il pensait qu'il pouvait le refaire sans crainte ».

La breuitas est employée ici pour sa fonction la plus élémentaire : celle du rapport efficace des informations nécessaires à la bonne compréhension de la cause. Dans ce dernier extrait cependant, Cicéron amorce le dispositif de persuasion : la répétition en polyptote du verbe credere, ainsi que le parallélisme entre la situation de 59 (regnanti) et celle de 55 (egenti et rogandi), instauré par les effets phoniques et renforcé par la cheville explicative nam, rendent audible la logique de répétition qui a gouverné la décision de Rabirius Postumus de prêter de l'argent au roi d'Égypte. La breuitas est ici employée non seulement pour résumer la situation, mais aussi pour rendre cette logique de répétition implacable et inattaquable.

41 La portée argumentative de la breuitas narrative est d'autant plus importante que les faits rapportés concernent la cause elle-même. Dans le Pro Caecina, Cicéron raconte ainsi les dispositions prises par son client Cécina contre Ébutius : accompagné d'amis, il décide d'aller sur les lieux qui font l'objet du litige, afin que la partie adverse en soit expulsée et que l'affaire puisse être portée en justice. Mais celui-ci l'attend dans la propriété, avec des hommes armés. L'épisode fait l'objet d'un traitement narratif particulièrement soigné de la part de Cicéron, car il lui permet en particulier de maintenir l'attention des juges en fin de narration. L'usage privilégié de la parataxe confère à la breuitas une charge dramatique qu'elle n'avait pas dans les premiers extraits :

Cicéron, Caec. 20 :

Cōnlǒcūntur. // 1 [ditrochée]

Dies ex utriusque [cōmmŏdō sūmìtur]. // 5 [dicrétique]

"On discute. On choisit un jour qui va à tout le monde.»

Cicéron, Caec. 20 :

Cum id partim [mīrārēntur], / par[tīm nōn crēedĕrent] // 7 [dispondée] + [spondée + crétique],

ecce ipse Aebutius in cas[tēllūm uēnit]. // 6 [dispondée]

«Certains s'étonnent, d'autres ne veulent pas y croire, et voici qu'Ébutius se

présente au château. »

Cicéron, Caec. 21 :

De castel[1اō dēscēndunt], // 3 [dispondée]

in fundum proficiscuntur. // 3

" Ils descendent du château, ils partent vers le domaine. »

Cicéron multiplie les compléments de temps et de lieu, afin de fournir à l'auditoire une idée précise des circonstances de cet épisode. L'emploi de la breuitas, ainsi que l'usage récurrent du présent de narration, répondent ici aux modalités mises en œuvre par Térence dans les passages commentés de L'Andrienne. Il s'agit bien de mettre sous les yeux les actions de l'intrigue. Mais le dispositif de persuasion va plus loin. L'arrivée d'Ébutius, mise en évidence par le déictique ecce, suscite sans doute, dans l'esprit des juges, la superposition de deux images : la représentation mentale du personnage de la narratio et la vision de la personne physique présente lors du procès. Ainsi, l'orateur fait coïncider la réalité construite dans la stratégie discursive et l'environnement judiciaire. Cette breuitas, associée à la parataxe et au présent de narration, est également employée dans le Pro Rabirio Postumo au moment où Cicéron évoque précisément le dernier emprunt octroyé par Rabirius Postumus à Ptolémée : 
Cicéron, Rab. Post. 5 :

Sup[plēx ěrāt rex], // 3 [ditrochée]

[mūltă rŏgābat], // 2 [dactyle + spondée]

omnia [pōllǐcěbātur] // 2 [dactyle + spondée]

«Le roi suppliait, il réclamait beaucoup, il promettait tout ».

43 à la fois sur l'accumulation d'éléments analogues et sur l'amplification. En effet, outre l'homéotéleute supplex / rex, on note que les deux premières incises forment un isokolon de 5 syllabes, tandis que la deuxième et la troisième, closes par la même clausule, suggèrent une dynamique ascendante, portée par l'hyperbole (multa... omnia) et l'allongement de l'énoncé (8 syllabes dans la dernière incise). Ces figures suggèrent l'insistance de Ptolémée, face à laquelle Rabirius Postumus s'est vu contraint d'obtempérer. La brièveté des énoncés est employée ici précisément pour sa simplicité apparente, propre à matérialiser, à travers un éventail d'outils sémantiques, phoniques et rythmiques, le piège qui s'est refermé sur Rabirius Postumus. La parataxe impose, dans l'esprit des juges, une chaîne d'images mentales susceptibles de reconstituer, par leur seule succession, cette corrélation entre l'attitude de Ptolémée et les actions menées par le client de Cicéron.

D'autre part, la breuitas permet à la fois de caractériser l'ethos de l'adversaire de manière efficace, et de l'attaquer. À ce titre, les procédés mis en œuvre dans le Pro Caecina illustrent, de façon prémonitoire, les conseils donnés dans l'Orator, où le style haché par incises et par membres est préconisé lorsqu'il s'agit de réfuter l'adversaire ou bien de dresser un portrait à charge. Les énoncés sont alors comparés à de petits poignards ${ }^{66}$.

Cicéron, Caec. 14 :

Is enim Caesenniae fuit Aebutius. // 5

Ne forte quaeratis [nūm prŏpīnquus ?] / - nihil alienus ; // $5+2$ [ditrochée]

amicus, aut a patre, aut [ā uǔrō trādĭtus ?] / - nihil minus. // $8+2$ [dicrétique]

Quis igitur? Ille, ille, quem supram [dēfōrmāui]]. // $2+5$ [dispondée]

«Ébutius fut l'homme de Césennia. Vous vous le demandez peut-être, était-ce un proche ? - Un étranger, rien de moins. Était-ce un ami envoyé par le père ou bien le mari ? - Pas du tout. Qui alors ? Lui, oui, lui, que j'ai décrit tout à l'heure. »

Dans cet extrait, on note à quel point Cicéron concentre les effets stylistiques. À la brièveté des énoncés s'associe une grande variété de figures : les répétitions (nihil... nihil ; ille... ille) et le dialogue fictif, dans lequel Cicéron prend à partie les juges, sans compter la diversité des clausules employées, toutes constituées cependant par la répétition du même motif rythmique. La brièveté piquante est donc portée ici par les questions rhétoriques, dans lesquelles l'orateur joue son propre rôle (quem supram deformaui), ou bien par l'ironie mordante (uir optimus) d'une caractérisation éthique qui prend l'exact contre-pied de toutes les actions rapportées précédemment. Cette brièveté véhémente prend donc tout son sens dans l'économie globale de la narratio, et vient ici conclure un portrait de l'adversaire dressé avec beaucoup de soin par l'orateur ${ }^{67}$. On le voit, la diversité des outils oratoires employés constitue une arme de choix, que Cicéron manie avec beaucoup d'habileté.

Cet emploi pathétique de la breuitas est également présent dans la narratio du Pro Rabirio Postumo, non pas pour attaquer Ptolémée, mais pour blâmer ceux qui ont osé porter l'affaire devant les juges.

Cicéron, Rab. Post. 6 :

Hinc primum exoritur [crīměn îllud] ; // 5 [ditrochée] 
senatum corruptum [ēssě dīcunt]. // 4 [ditrochée]

O di [īmmōrtāles] ! // 3 [dispondée]

Haec est illa exoptata iudicio[rūm sěuērĭtas] ? // 6 [trochée + crétique]

Corruptores nostri [caūsām dīcunt] ; // 4 [dispondée]

nos qui corrupti sumus non dicimus? // 6

Quid ergo? // 2

Senatum defendam [hōc lŏcō, iūdǐces] ? // 5 [dicrétique]

"Voilà d'où vient le premier chef d'accusation. Ils disent que le Sénat a été corrompu. Dieux immortels! Voilà cette sévérité des juges, tant attendue ! Ceux qui nous ont corrompus sont mis en cause. Et pas nous, qui avons été corrompus? Mais alors! Dois-je défendre maintenant le Sénat, juges?»

la narratio proposées par Cicéron, notamment dans l'usage répété et différencié d'une citation de L'Andrienne de Térence, on voit à quel point Cicéron est de plus en plus influencé par le dispositif dramatique et attentif à l'interaction entre l'orateur et son public. Il finit ainsi par considérer la brièveté de la narratio avant tout comme une qualité de la réception du discours par le public, alliée au charme et à l'agrément (suauitas). Les relevés statistiques dans les discours de défense successifs ne révèlent cependant aucune évolution claire dans la pratique cicéronienne de la breuitas. Il s'agit d'un procédé complexe qui ne peut, en aucun cas, se résumer à la simple limitation du nombre de mots. L'analyse du Pro Caecina et du Pro Rabirio Postumo montre ainsi que la breuitas s'exprime par une palette d'effets phoniques et rythmiques: on comprend pourquoi Cicéron tient tellement à dissocier brièveté et sécheresse.

Cependant, à l'issue de cette analyse, les questions demeurent plus nombreuses que les certitudes. Si les définitions successives de la narratio oratoire, en particulier de la breuitas, illustrent le souci constant chez Cicéron de faire évoluer sa théorie en fonction de la réalité du terrain et de son expérience, la complexité des concepts en jeu soulève bien des interrogations. Les catégories de clarté et de vraisemblance, mais aussi d'agrément et d'évidence, mériteraient une attention particulière, dans la mesure où elles nous invitent à interroger les rapports que peut entretenir la rhétorique avec l'histoire littéraire et la philosophie. 
51 Par ailleurs, si, comme je l'ai montré, l'attention de Cicéron portée aux interactions entre l'orateur et son public lui permet de renouveler la conception de la breuitas, et de conférer à la narratio une puissance d'évocation qui dépasse la simple fonction informative, une part d'ombre n'en demeure pas moins sur la réalité de ces interactions. Il serait sans doute instructif de croiser les modèles d'analyse contemporains proposés à la fois pour les formes narratives et pour le discours, en particulier ceux issus des théories de Searle sur les actes illocutoires ${ }^{69}$.

Enfin, l'analyse comparative montre à quel point les statistiques fournissent une première banque de données, qu'il convient de compléter par des études stylistiques prenant en considération les multiples fonctions de la breuitas : résumé, caractérisation éthique, expression de la véhémence. Cette polyvalence suggère la nécessité d'une analyse plurielle et globale de chaque narratio, appréhendée comme une architecture dans laquelle l'art de l'orateur se mesure à sa faculté de mêler infiniment un nombre restreint d'outils. Ainsi, comme le souligne A. von Albrecht, «the attribution of stylistic characteristics to individual sections of an oration is not subject to a mechanical code of rhetorical rules, all the more since the structure of the orations is often conditioned by other factors ${ }^{70} »$.

\section{BIBLIOGRAPHIE}

\section{Textes anciens}

Cicéron, Discours $=$ Orationes. $11, \mathrm{XXI}$, Division de l'art oratoire $=$ Partitiones oratoriae ; Topiques = Topica, éd. et trad. par H. BORNECQUE, CUF, Paris, Les Belles Lettres, 1960.

Rhétorique à Herrenius, texte établi et trad. par G. ACHARD, CUF, Paris, Les Belles Lettres, 1989.

\section{Études modernes}

ACHARD G. 1981, Pratique rhétorique et idéologie politique dans les discours optimates de Cicéron, Mnemosyne. Suppl. 68, Leyde, Brill.

ALBRECHT M. von 2003, Cicero's Style: A Synopsis, Mnemosyne. Suppl. 245, Leyde, Brill.

AUBERT S. 2010, «La polémique cicéronienne contre Atticistes et Stoïciens autour de la santé du style », in P. CHIRON, C. LÉVY (dir.), Les noms du style dans l'Antiquité gréco-latine, Bibliothèque d'études classiques 57, Louvain, Peeters, p. 87-111.

AUMONT J. 1996, Métrique et stylistique des clausules dans la prose latine : de Cicéron à Pline le Jeune et de César à Florus, Travaux de linguistique quantitative 56, Paris, Champion.

BETTINI M. 2006, « Mythos/Fabula: Authoritative and Discredited Speech », HR 45, p. 195-212. 
BUREAU B., NICOLAS C. 2013, «Argumentum et fiction dramatique dans le Commentaire de Donat à Térence ", in C. BRÉCHET, A. VIDEAU, R. WEBB (dir.), Théorie et pratique de la fiction à l'époque impériale, Textes, images et monuments de l'Antiquité au Haut Moyen Âge, Paris, Picard, p. 99-122 [en ligne]. URL : https://www.cairn.info/theories-et-pratiques-de-la-fiction-a-l-epoqueimp--9782708409408-p-99.htm [consulté le 4 janvier 2018] ; DOI : 10.3917/pica.brech.2013.01.0099. CALBOLI-MONTEFUSCO L. 1988, Exordium Narratio Epilogus. Studi sulla teoria retorica greca e romana delle parti del discorso, Bologne, CLUEB.

- 2010, «Laustera suauitas de l'orateur », in P. CHIRON, C. LÉVY (dir.), Les noms du style dans l'Antiquité gréco-latine, Bibliothèque d'études classiques 57, Louvain, Peeters, p. 113-129.

CRAIG C. P. 2002, «A Survey of Selected Recent Works on Rhetorica and Speeches », in J. M. MAY (dir.), Brill's Companion to Cicero. Oratory and Rhetoric, Leyde, Brill, p. 503-532.

DOMINICY M., FRÉDÉRIC M. (dir.) 2001, La mise en scène des valeurs. La rhétorique de l'éloge et du blâme, Textes de base en sciences des discours, Lausanne, Delachaux et Niestlé.

DROSS J. 2010, «Qu'est-ce qu'un discours évident ? Les rapports entre l'évidence et la clarté dans l' Institution Oratoire ", in P. CHIRON, C. LÉVY (dir.), Les noms du style dans l'Antiquité gréco-latine, Bibliothèque d'études classiques 57, Louvain, Peeters, p. 233-252.

FANTHAM E. 2004, The Roman World of Cicero's De Oratore, Oxford, Oxford University Press. FORMARIER M. 2013, « Discours et ethos viril chez Cicéron et Quintilien », in C. GUÉRIN, G. SIOUFFI, S. SORLIN (éd.), Le rapport éthique au discours. Histoire, pratiques, analyses, Berne, P. Lang, p. 177-195. GAINES R. N. 2002, Cicero's Partitiones Oratoriae and Topica: Rhetorical Philosophy and Philosophical Rhetoric, in M. James, M. May (éd.), Brill's Companion to Cicero Oratory and Rhetoric, Leyde, Brill, p. $445-480$.

GALIMBERTI BIFFINO G. 2010, «L'elegantia chez Fronton : raffinement de l'architecture de la phrase et du choix des mots ", in M. BARATIN, C. LÉVY, R. UTARD, A. VIDEAU (dir.), Stylus : la parole dans ses formes. Mélanges en l'honneur du professeur Jacqueline Dangel, Rencontres 11, Paris, Classiques Garnier, p. 215-226.

GILDENHARD I. 2011, Creative Eloquence. The Construction of Reality in Cicero's Speeches, Oxford, Oxford University Press.

GUÉRIN C. 2009, Persona. L'élaboration d'une notion rhétorique au $I^{e r}$ siècle av. J.-C. I, Antécédents grecs et première rhétorique latine, Textes et Traditions 18, Paris, Vrin.

- 2011, Persona. L'élaboration d'une notion rhétorique au $I^{e r}$ siècle av. J.-C. II, Théorisation cicéronienne de la persona oratoire, Textes et Traditions 21, Paris, Vrin.

- 2014, «Oratorum bonorum duo genera sunt. La définition de l'excellence stylistique et ses conséquences théoriques dans le Brutus », in S. AUBERT-BAILLOT, C. GUÉRIN (dir.), Le Brutus de Cicéron. Rhétorique, politique et histoire culturelle, Mnemosyne. Suppl. 371, Leyde, Brill, p. 161-192.

JOHNSON W. R. 1971, Luxuriance and Economy. Cicero and the Alien Style, Berkeley, University of California Press.

LAURAND L. 1965, Études sur le style des discours de Cicéron, Amsterdam, Hakkert.

LEVENE D. S. 2004, « Reading Cicero's Narratives », in J. POWELl, J. PATERSON (ed.), Cicero the Advocate, Oxford, Oxford University Press, p. 117-146. 
LÉVY C. 2010, «Venustas chez Cicéron », in P. CHIRON, C. LÉVY (dir.), Les noms du style dans l'Antiquité gréco-latine, Bibliothèque d'études classiques 57, Louvain, Peeters, p. 165-177.

MAY J. M. 2002, « Ciceronian Oratory in Context », in Id. (dir.), Brill's Companion to Cicero. Oratory and Rhetoric, Leyde, Brill, p. 49-70.

MICHEL A. 2003, Les rapports de la rhétorique et de la philosophie dans l'œuvre de Cicéron. Recherches sur les fondements philosophiques de l'art de persuader, $2^{\mathrm{e}}$ éd. [1 $1^{\mathrm{re}}$ éd : 1960], Bibliothèque d'études classiques 34, Louvain, Peeters.

NARDUCCI E. 2009, Cicerone. La parole e la politica, Storia e sacietà, Rome, Laterza.

O'BANION J. 1987, « Narration and Argumentation: Quintilian on Narratio as the Heart of Rhetorical Thinking », Rhetorica 5, p. 325-351.

POWELl J., PATERSON J. 2004, « Introduction », in Eid. (ed.), Cicero the Advocate, Oxford, Oxford University Press, p. 1-57.

RODDEN J. 2008, « How Do Stories Convince Us? Notes towards a Rhetoric of Narrative », College Literature 35, p. 148-173.

SZNAJDER L. 2013, "Quelques pistes dans le champ lexical de la fiction en latin », in C. BRÉCHET, A. VIDEAU, R. WEBB (dir.), Théorie et pratique de la fiction à l'époque impériale, Textes, images et monuments de l'Antiquité au Haut Moyen Âge, Paris, Picard, p. 49-62 [en ligne]. URL : https:// www.cairn.info/theories-et-pratiques-de-la-fiction-a-l-epoque-imp--9782708409408-p-49.htm [consulté le 4 janvier 2018] ; DOI : 10.3917/pica.brech.2013.01.0049.

USHER S. 2008, Cicero's Speeches: The Critic in Action, Oxford, Aris \& Phillips.

WEBB R. 1997, « Mémoire et imagination : les limites de l'enargeia dans la théorie rhétorique grecque », in C. LÉVY, L. PERNOT (dir.), Dire l'évidence. Philosophie et rhétorique antiques, Paris,

L'Harmattan, p. 229-248.

\section{NOTES}

1. Cicéron, Inu., I, 27 : Narratio est rerum gestarum aut ut gestarum expositio.

2. Voir CALBOLI-MONTEFUSCO 1988, p. 34.

3. Cicéron, Inu., I, 28 : de narratione ea, quae causae continet expositionem [...].

4. Voir LEVENE 2004, p. 117. Néanmoins, cette disposition n'est pas toujours respectée, voir CALBOLI-MONTEFUSCO 1988, p. 37-40.

5. Cicéron, Inu., I, 28 : Oportet igitur eam tres habere res : ut brevis, ut aperta, ut probabilis sit. Sur les origines grecques de cette tripartition, voir CALBOLI-MONTEFUSCO 1988, p. 66-69 et 72.

6. O'BANION 1987, p. 343 : " Narratio was constituted of the tensions of the "plot" of the case, its "fleshing out" through characterisation and dialogue, and the elucidation that perspective of continua brings ". C. Guérin (2009, p. 327-329) montre que, dès le De inuentione, Cicéron est très sensible à l'ensemble des caractéristiques des individus dont il est question et ne se contente pas du statut social. La caractérisation morale intervient ici comme une préparation de la discussion. Voir également MAY 2002, p. 60-61; GILDENHARD 2011, p. 21-73.

7. Voir CALBOLI-MONTEFUSCO 1988, p. 65. 
8. Sur l'influence de l'expérience pratique sur la conception cicéronienne de la parole publique, voir POWELL, PATERSON 2004, p. 43-44.

9. Pour comparer avec le texte de la Rhétorique à Hérennius, voir Rhet. Her., I, 12. Sur les antécédents grecs, voir CALBOLI-MONTEFUSCO 1988, p. 35.

10. Toutes les traduction sont personnelles.

11. Voir GUÉRIN 2009, p. 329.

12. Voir Rhet. Her., I, 13.

13. Voir G. ACHARD dans l'édition de la Rhétorique à Hérennius, CUF, p. 13, n. 62. C'est Quintilien, Inst., IV, 2, 31, qui explicite cette source: Eam plerique scriptores maximeque qui sunt ab Isocrate uolunt esse lucidam, breuem, ueri similem. Neque enim refert an pro lucida perspicuam, pro ueri simili probabilem credibilemue dicamus. On remarque que l'hétérogénéité terminologique ne semble donc pas poser question - elle ne touche d'ailleurs pas la brièveté, toujours évoquée par l'adjectif breuis, l'adverbe breuiter ou le nom breuitas. On trouve un témoignage de cette tradition notamment dans la Rhétorique à Alexandre, 1438a, 21. Voir GUÉRIN 2009, p. 327.

14. Voir Rhet. Her., I, 14.

15. Voir Cicéron, de Orat., II, 75-76.

16. Par ex. les cinq parties de la rhétorique : inuentio, dispositio, elocutio, actio et memoria. Voir Cicéron, de Orat., II, 79.

17. Même si la datation de ce traité pose problème (entre 54 et 44 ), comme le souligne H. Bornecque (CUF, p. XI-XII), il est de toute façon postérieur au De oratore, et antérieur à l'Orator.

18. Contrairement à ce que affirme R. N. Gaines (2002, p. 452) dans son commentaire.

19. CALBOLI-MONTEFUSCO 2010, p. 115.

20. Cicéron, Part. 19 : Communia autem simplicium coniunctorumque sunt haec quinque quasi lumina, dilucidum, breue, probabile, illustre, suaue, «Les qualités communes aux mots isolés ou regroupés sont les cinq suivantes, semblables à des lumières : la clarté, la brièveté, la vraisemblance, l'évidence et l'agrément ». Voir Quintilien, Inst., IV, 2, 107. Sur cette question des rapports entre elocutio et narratio, voir CALBOLI-MONTEFUSCO 1988, p. 70-71.

21. Voir à ce sujet Quintilien, Inst., IV, 2, 63 : Illa quoque narrationi apta, ita ceteris quoque partibus communis est uirtus, quam Theodectes huic uni proprie dedit; non enim magnificam modo uult esse, uerum etiam iucundam expositionem. Sunt qui adiciant his euidentiam, quam enargeia Graece uocatur, "Ces principes sont adaptés à la narration, mais il y a aussi une qualité, commune aux autres parties du discours, que Théodecte lui attribue en propre : il veut que l'exposé soit dans un style élevé, et agréable. Certains ajoutent à cela l'évidence, appelée enargeia en grec ». Sur ce passage, voir CALBOLI-MONTEFUSCO 1988, p. 70-73.

22. GUÉRIN 2014, p. 169.

23. Cicéron, Orat. 122 : rem breuiter exponere et probabiliter et aperte, ut quid agatur intellegi possit, " exposer les faits de façon brève, vraisemblable et claire, pour que l'on puisse comprendre de quoi il s'agit». 
24. Cicéron, Orat. 139 : Atque alias etiam dicendi quasi uirtutes sequetur, breuitatem, si res petet, «Il recherchera d'autres qualités stylistiques, comme la brièveté, si la situation l'exige ».

25. MICHEL 2003, p. 438.

26. Voir Cicéron, Orat. 137-138.

27. Cicéron, Inu., I, 28 : si inde incipiemus narrare unde necesse erit, et si non ab ultimo initio repetere uolemus. Voir Quintilien, Inst., IV, 2, 40 : si inde coeperimus rem exponere, unde ad iudicem pertinet.

28. Cicéron, Inu., I, 28 : si summatim non particulatim narrabimus.

29. Cicéron, Inu., I, 28 : si transitionibus nullis utemur.

30. Cicéron, Inu., I, 28 : si non deerrabimus ab eo quod coeperimus exponere. Voir Quintilien, Inst., IV, 2, 40 : si nihil extra causam dixerimus.

31. Cicéron, Inu., I, 28 : et ne bis aut saepius idem dicamus cauendum est.

32. Cicéron, Inu., I, 28 : si exitus rerum ita ponemus ut ante quoque quae facta sint sciri possint, tametsi nos reticuerimus. Voir Quintilien, Inst., IV, 2, 41 : et quotiens exitus rei satis ostendit priora, debemus hoc esse contenti, quo reliqua intelleguntur.

33. Cicéron, Inu., I, 28 : et omnino non modo id quod obest, sed etiam id quod neque obest neque adiuuat satius est praeterire.

34. Cicéron, Inu., I, 28 : Ac multos imitatio breuitas decipit, ut, cum se breuis putent esse, longissimi sint ; cum dent operam ut res multas breui dicant, non ut omnino paucas res dicant et non plures quam necesse sit. Comme l'explique L. Calboli-Montefusco (2010, p. 129), la réussite de l'éloquence, pour Cicéron, est l'adéquation entre un contenu solide et bien mis en forme, et l'usage, dans un second temps, des figures de style. Voir aussi fantHAM 2004, p. 254.

35. Sur l'argumentum, voir notamment CALBOLI-MONTEFUSCO 1988, p. 44-45; BETTINI 2006, p. 209 ; BUREAU, NICOLAS 2013, p. 99 ; SZNAJDER 2013, p. 53-54.

36. Point commun que rappelle Quintilien, Inst., IV, 2, 53 : Est autem quidam et ductus rei credibilis, qualis in comoediis etiam et in mimis, «Il y a une manière de présenter l'affaire qui est vraisemblable, comme dans les comédies et les mimes». Credibilis est ici employé au sens de ueri similis (voir IV, 2, 52 : Credibilis autem erit narratio...).

37. Sur ces deux définitions de la breuitas et sur la critique du stoïcisme dans ce passage, voir AUBERT 2010, p. 92.

38. Voir notamment Cicéron, Brut. 285-291; Orat. 28-29. Sur l'objet précis des critiques adressées mutuellement par Cicéron et le mouvement atticiste, voir NARDUCCI 2009, p. 365-388 ; AUBERT 2010 ; GUÉRIN 2011, p. 340-349.

39. Sur l'emploi de uenustas comme une qualité de l'homme romain, et non un caractère efféminé, voir LÉVY 2010, p. 175 ; FORMARIER 2013, p. 183.

40. Procédé issu de la sermocinatio, voir GUÉRIN 2009, p. 330.

41. Sur la uarietas comme outil pour éviter l'écœurement ou l'ennui, voir NARDUCCI 2009, p. 317-318; CALBOLI-MONTEFUSCO 2010, p. 122.

42. Même raisonnement chez Quintilien, Inst., IV, 2, 47.

43. Cicéron met ainsi en regard le style restreint et le style concis. Voir GUÉRIN 2014, p. 174. 
44. Sur ce passage, voir AUBERT 2010, p. 95.

45. Sur les plaisanteries employées par Crassus lors de cette affaire, voir aussi Cicéron, de Orat., II, 221.

46. MAY 2002, p. 49.

47. GUÉRIN 2014, p. 182.

48. Même raisonnement dans Brut. 290.

49. Sur la défense de l'agrément contre la sécheresse atticiste, associée au stoïcisme, voir LÉVY 2000, p. 142-143; MICHEL 2003, p. 439 ; AUBERT 2010, p. 88.

50. MICHEL 2003, p. 330.

51. Sur le rapport entre euidentia et le procédé qui consiste à mettre sous les yeux, voir DROSs 2010, p. 239. Le transfert du terme euidentia de la philosophie à la rhétorique est opéré par Quintilien, voir WEBB 1997, p. 229.

52. Voir WEBB 1997, p. 233.

53. Voir WEBB 1997, p. 230.

54. Voir ce qu'en dit Antoine dans Cicéron, de Orat., II, 194. Voir NARDUCCI 2009, p. 63.

55. Sur la dimension émotionnelle de l'évidence rhétorique, voir WEBB 1997, p. 230 ; DROSs 2010, p. 243. Procédé reconnu aujourd'hui dans la théorie du storytelling, voir RODDEN 2008, p. 167 : « As the narrative weaves images and moves from motif to motif, it appeals primarily to the reader's imagination, not to his reason ». Voir également GALIMBERTI BIFFINO 2010, p. 219.

56. Cicéron, Orat. 138.

57. Cicéron, Brut. 290 : in scaena esse Roscium intellegat. Sur le caractère théâtral de la performance judiciaire, voir NARDUCCI 2009, p. 60-61.

58. Voir Cicéron, Orat. 210, et Quintilien, Inst., II, 4, 59.

59. L'état de l'art sur cette question est dressé par MAY 2002, p. 49-50; CRAIG 2002, p. 515-517 ; POWELL, PATERSON 2004, p. 52-57. Voir également LEVENE 2004, p. 118-121 et 138-141. D. S. Levene prend le parti de considérer aussi l'exordium dans ses analyses, afin d'évaluer le rapport entre les informations données en introduction et la narratio à proprement parler. Dans le cadre de relevés statistiques, la comparaison entre exordium et narratio sera facilitée par les tableaux présentés dans JOHNSON 1971, p. 67.

60. Pour l'état de la question, voir CRAIG 2002, p. 524-531. Sur l'apport de l'ouvrage de W. R. Johnson, voir ibid., p. 526.

61. Voir en particulier AUMONT 1996, p. 14-16.

62. MICHEL 2003, p. 441.

63. GUÉRIN 2014, p. 184.

64. CRAIG 2002, p. 529.

65. USHER 2008, p. 38.

66. Cicéron, Orat. 224 : in his, quibus ut pugiunculis uti oportet, «dans [les incises] qu'il convient d'employer comme de petits poignards ».

67. Voir notamment Cicéron, Caec. 14, où Ébutius est présenté comme le stéréotype du brigand. 
68. M. VON ALBRECHT (2003, p. 80 ) souligne ainsi que la narratio est d'autant plus efficace que le style qu'elle emploie est simple, ou du moins, semble l'être : « its style should be simple, almost colloquial. Here the speaker should avoid ostentatious rhetoric and, of course, the artifices of historiographical style. Syntax and rhythm may be treated with a certain (studied) negligence ».

69. La mise en perspective de ces modèles et de la tradition antique a été menée avec brio dans DOMINICY, FRÉDÉRIC (dir.) 2001.

70. ALBRECHT 2003, p. 84.

\section{RÉSUMÉS}

La définition de la narratio cicéronienne comme brève, claire et vraisemblable pose en réalité la question de la fonction de la narration par rapport aux autres modalités du discours. En se concentrant sur la breuitas, l'article montre que Cicéron considère cette qualité comme portant sur la réception du discours par le public et non sur des notions de longueur ou de brièveté au sens moderne de ces termes. Il s'agit d'une forme particulière de densité du discours.

The definition that Cicero gives of narratio as brief, clear and plausible poses the question of the function of the narrative in relation to the other modalities of the discourse. By focusing on breuitas, the paper shows that Cicero considers this quality as dealing with the reception of speech by the public and not on notions of length or brevity in the modern sense of these terms, and is a particular form of speech density. triumviri. The similarities and the dialogue established between the poems reveal a permanent feature of the civil war poetry: a self-reflexive dimension and a will to anchor the poetry in the politic sphere.

\section{INDEX}

Mots-clés : persuasion, brièveté, narration, rhétorique ancienne oeuvrecitee Rhétorique à Alexandre, Rhétorique à Herennius nomsmotscles Aristote, Cicéron, Isocrate, Quintilien, Térence Keywords : persuasion, brevity, narrative, ancient rhetoric 